06

\title{
Выращивание ориентированных пленок AIN на подложках сапфира методом плазмоактивированного атомно-слоевого осаждения
}

\author{
() В.А. Тарала, А.С. Алтахов, М.Г. Амбарцумов, В.Я. МартенС
}

Северо-Кавказский федеральный университет, Ставрополь

E-mail: vitaly-tarala@yandex.ru

Поступило в Редакцию 12 июля 2016 г.

Исследована возможность использования метода плазмоактивированного атомно-слоевого осаждения для выращивания ориентированных пленок AlN на подложках $\mathrm{Al}_{2} \mathrm{O}_{3}$ при температурах менее $300^{\circ} \mathrm{C}$. Проведены исследования образцов методами рентгенофазового анализа и эллипсометрии. Показано, что при длительностях плазменной экспозиции боле $20 \mathrm{~s}$ осаждаются пленки, обладающие показателем преломления, равным $2.03 \pm 0.03$. На рентгенограм-

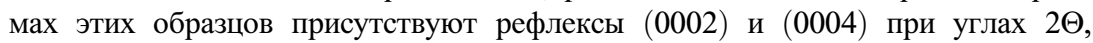
равных $35.7^{\circ}$ и $75.9^{\circ}$, характерные для гексагонального политипа AIN. У наилучшего образца для рефлекса (0002) ширина кривой качания на полувысоте интенсивности (FWHM) составила порядка $162 \pm 11$ arcsec.

DOI: 10.21883/PJTF.2017.01.44091.16401

Тонкие пленки нитрида алюминия (AlN) перспективны для изготовления холодных катодов [1], силовых приборов [2], газовых сенсоров [3], УФ-светодиодов, фотодетекторов [4], пьезоэлектрических RF-MEMS устройств [5], а также в качестве буферных слоев для роста пленок нитридов галлия [6]. Для этих применений важно получать кристаллические пленки, а также контролировать их кристаллографическую ориентацию.

Из-за отсутствия доступных монокристаллических подложек нитрида алюминия пленки AlN осаждают на инородные подложки $(\mathrm{Si}$, $\mathrm{SiC}, \mathrm{Al}_{2} \mathrm{O}_{3}$ ), отличающиеся коэффициентом термического расширения и периодом кристаллической решетки. По этой причине в синтезированных слоях возникают сильные внутренние механические напряжения, а также высокие плотности дефектов. Снизить величину внутренних 
механических напряжений можно путем понижения температуры формирования пленок.

Как правило, высококачественные ориентированные кристаллические пленки AlN выращивают методами химического осаждения из газовой фазы (CVD - Chemical Vapor Deposition) [7-9] на подложках сапфира при температурах более $840^{\circ} \mathrm{C}$. Эти пленки имеют ширину кривой качания на полувысоте интенсивности (FWHM) порядка 11 $\operatorname{arcsec}$ [9]. В то же время методом магнетронного распыления (MS Magnetron Sputtering) [10] осаждаются пленки при температурах порядка $500^{\circ} \mathrm{C}$, но у этих слоев величина $\mathrm{FWHM}>2^{\circ}$. Методами плазмоактивированного атомно-слоевого осаждения (PEALD) выращиваются аморфные или поликристаллические пленки нитрида алюминия [11-16]. При этом в литературе имеются противоречивые данные о температурах начала роста кристаллических пленок. Так, в [12] выдвинуто предположение, что кристаллические пленки можно вырастить только при температурах $(T)$ более $300^{\circ} \mathrm{C}$. В работе [14] кристаллические пленки выращены при $T=250^{\circ} \mathrm{C}$, а в работе [13] показана возможность роста при $T \geqslant 100^{\circ} \mathrm{C}$. Во всех этих случаях осаждались покрытия без выраженной ориентации. Между тем об успехах синтеза ориентированных пленок на подложке сапфира с буферным слоем GaN сообщается в работе [16], однако этот результат был достигнут при температурах порядка $500^{\circ} \mathrm{C}$. В данной работе представлены результаты экспериментальных исследований, свидетельствующие о возможности осаждения ориентированных пленок AlN при температурах подложки сапфира менее $300^{\circ} \mathrm{C}$, и обсуждается влияние температуры подложки и длительности плазменной экспозиции на кристалличность этих пленок.

B настоящее время гетероэпитаксиальные пленки AlN c максимально высокой кристалличностью выращиваются на подложках сапфира $\left(\mathrm{Al}_{2} \mathrm{O}_{3}\right)$, поэтому подложки данного материала были выбраны для нашего исследования. Синтез пленок осуществлялся при помощи установки PEALD TFS-200 производства компании Beneq (Финляндия). Во всех экспериментах рабочая частота ВЧ-генератора составляла $13.56 \mathrm{MHz}$, мощность - $200 \mathrm{~W}$, расход азота через камеру реактоpa $200 \mathrm{sccm}$, а через реактор $300 \mathrm{sccm}$. После выхода на температурный режим $\left(210-280^{\circ} \mathrm{C}\right)$ поверхность подложки в течение $60 \mathrm{~s}$ обрабатывали плазмой газовой смеси водорода $(80 \mathrm{sccm})$ и азота $(20 \mathrm{sccm})$. Плазма этой смеси использовалась в качестве источника азота в циклическом процессе осаждения пленки. Первой стадией цикла являлась 
подача в реактор триметилалюминия (ТМА), являющегося источником алюминия. Испаритель с ТМА был термостатирован при температуpe $18^{\circ} \mathrm{C}$. Во всех экспериментах длительность импульса подачи ТМА составляла $0.05 \mathrm{~s}$. Затем в течение времени $\tau_{P U R}=30 \mathrm{~s}$ проводилась вентиляция реактора с целью удаления избытков ТМА и продуктов его взаимодействия с подложкой. После этого поверхность подложки обрабатывали плазмой газовой смеси водорода и азота. Длительность плазменной экспозиции $\left(\tau_{P E}\right)$ изменяли от 3 до $30 \mathrm{~s}$. Финальной стадией цикла была вентиляция реактора длительностью $10 \mathrm{~s}$. Количество циклов осаждения подбирали таким образом, чтобы толщины пленок были в диапазоне $35-40 \mathrm{~nm}$.

Скорость роста (GR) оценивали как отношение толщины пленки к количеству циклов осаждения. Толщину пленки измеряли при помощи спектрального эллипсометра SE-800 (Sentech, Германия). Было установлено, что в диапазоне температур $210-250^{\circ} \mathrm{C}$ и при $\tau_{P E} \leqslant 6$ s GR составила $0.100 \pm 0.005 \mathrm{~nm} /$ cycle. При уменьшении $\tau_{P E}$ до $3 \mathrm{~s}$ величина GR снижалась до $0.085 \pm 0.005 \mathrm{~nm} /$ cycle, а при повышении температуры до $280^{\circ} \mathrm{C}$ она увеличивалась до $0.108 \pm 0.005 \mathrm{~nm} /$ сусlе. Так как отсутствие зависимости GR от $T$ указывает на самоограниченность процесса роста, было сделано предположение, что при температурах менее $250^{\circ} \mathrm{C}$ образцы осаждаются в режимах атомно-слоевого осаждения, а при более высоких температурах синтезируются в условиях, похожих на химическое осаждение из газовой фазы.

Исследования зависимости величины показателя преломления $(n)$ от условий осаждения позволили обнаружить, что для образцов, выращенных при $\tau_{P E}$ более $6 \mathrm{~s}$, значение $n$ на длине волны $633 \mathrm{~nm}$ достигает величины $2.01 \pm 0.05$. При этом показатель преломления практически не зависел от выбора температуры осаждения. Незначительное уменьшение $n$ до $1.95 \pm 0.05$ происходило при снижении $\tau_{P E}$ до $3 \mathrm{~s}$. Принимая во внимание, что у пленок AlN показатель преломления снижается с уменьшением кристалличности, вероятно, что $3 \mathrm{~s}$ плазменной экспозиции недостаточно для полного превращения хемосорбированных частиц в слой кристаллического нитрида алюминия.

С целью анализа микроструктуры пленок были проведены рентгенофазовые исследования в диапазоне углов $2 \Theta$ от $30^{\circ}$ до $80^{\circ}$ при помощи дифрактометра ARLX'TRA (Thermo Fisher Scientific), оснащенного параболическим зеркалом Гёбеля и тонкопленочным коллиматором. Эти исследования показали, что у образцов $\mathrm{AlN} / \mathrm{Al}_{2} \mathrm{O}_{3}$,

Письма в ЖТФ, 2017, том 43, вып. 1 
выращенных при $\tau_{P E}=3 \mathrm{~s}$, на рентгенограммах, измеренных в геометрии Брегга-Брентано (XRD), имеются только связанные с подложкой сапфира рефлексы (0006) при углах $2 \Theta$ порядка $41.7^{\circ}$. Отсутствие рефлексов нитрида алюминия свидетельствовало об аморфной структуре пленок. У образцов, синтезированных при $\tau_{P E}=6 \mathrm{~s}$, на рентгенограммах появлялись дополнительно интенсивные рефлексы с максимумами при углах $2 \Theta$, равных $35.7 \pm 0.1^{\circ}$ (см. рисунок, $a$ ), за которые ответственны отражения от плоскостей (0002) гексагонального политипа нитрида алюминия [7]. При температурах $250-280^{\circ} \mathrm{C}$ и при $\tau_{P E} \geqslant 20 \mathrm{~s}$ на рентгенограммах появлялись отражения от плоскостей более высокого порядка (0004), что свидетельствовало о повышении кристалличности пленок с увеличением длительности плазменной экспозиции.

Следует отметить, что у образцов, осажденных при температуpe $210^{\circ} \mathrm{C}$ даже при $\tau_{P E}=30 \mathrm{~s}$, рефлексов (0004) не наблюдалось. Данное обстоятельство свидетельствовало о необходимости более значительного увеличения длительности плазменной экспозиции для повышения кристалличности пленок при снижении температуры процесса их синтеза. Однако, по нашему мнению, процессы с $\tau_{P E}>30 \mathrm{~s}$ с точки зрения практического использования метода PEALD экономически не эффективны.

Далее были проведены исследования пленок методом кривых качания $(R c$ - rocking curve). На рисунке $b$, для одного из образцов, выращенных при $T \geqslant 250^{\circ} \mathrm{C}$ и $\tau_{P E} \geqslant 10 \mathrm{~s}$, представлена кривая качания, измеренная для угла $2 \Theta=35.7^{\circ}$. Так же, как в работах $[7,17]$, формы $R_{c}$ описывались суммой двух кривых Гаусса. Отметим, что природа узкой и интенсивной составляющей $R c$ ( $D$-кривая) связана с дифракцией от плоскостей (0002) (см. рисунок, c). Что касается широкой coставляющей ( $R$-кривая), то она обусловлена диффузным рассеянием, возникающим в тонких пленках из-за шероховатости границ раздела, малого диаметра кристаллитов, а также высокой плотности дислокаций. Проведенные исследования этих образцов показали, что ширина $R$ кривой на полувысоте интенсивности $\left(\mathrm{FWHMR}_{R}\right)$ составляет порядка $1.6^{\circ} \pm 0.4^{\circ}$, а у $D$-кривой $\left(\mathrm{FWHM}_{D}\right)$ не превышает $0.045^{\circ} \pm 0.005^{\circ}$. Отношение интенсивностей $D$-кривой к $R$-кривой $\left(I_{D} / I_{R}\right)$ достигает величин $4.5 \pm 1.5$. Из-за более высокой интенсивности $D$-кривой, по сравнению с интенсивностью $R$-кривой, ширина $R c$ на полувысоте интенсивности $\left(\mathrm{FWHMR}_{R c}\right)$ и величина $\mathrm{FWHM}_{D}$ были сопоставимы (см. рисунок, $c$ ).

Письма в ЖТФ, 2017, том 43, вып. 1 

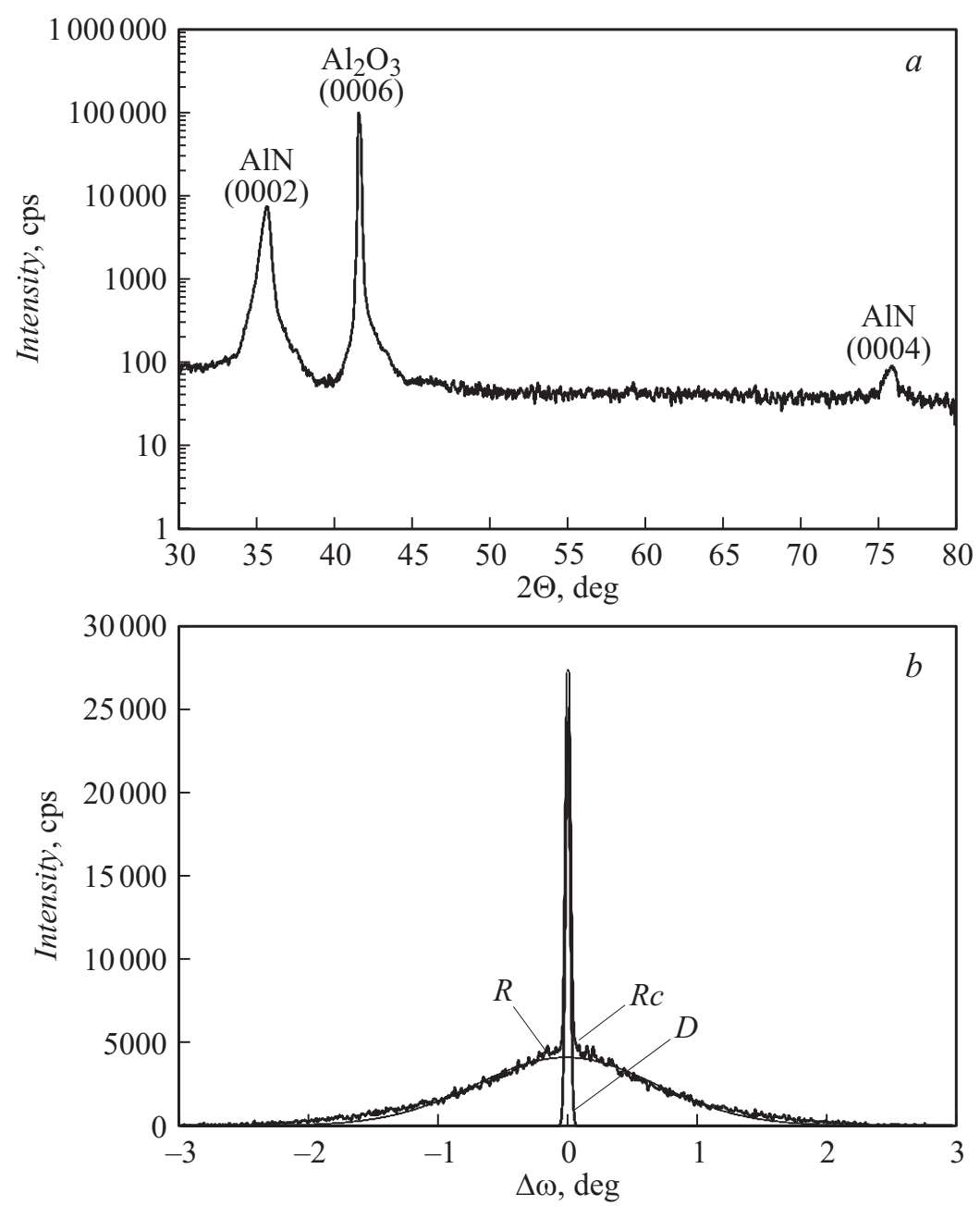

Результаты рентгеновских исследований: $a-$ типичная кривая рентгенофазового анализа; $b-$ кривая качания; $c-$ центральная часть кривой качания в увеличенном масштабе.

При снижении температуры до $210^{\circ} \mathrm{C}$ происходило уменьшение величины $I_{D} / I_{R}$ до $0.75 \pm 0.30$ на фоне снижения интенсивности

Письма в ЖТФ, 2017, том 43, вып. 1 


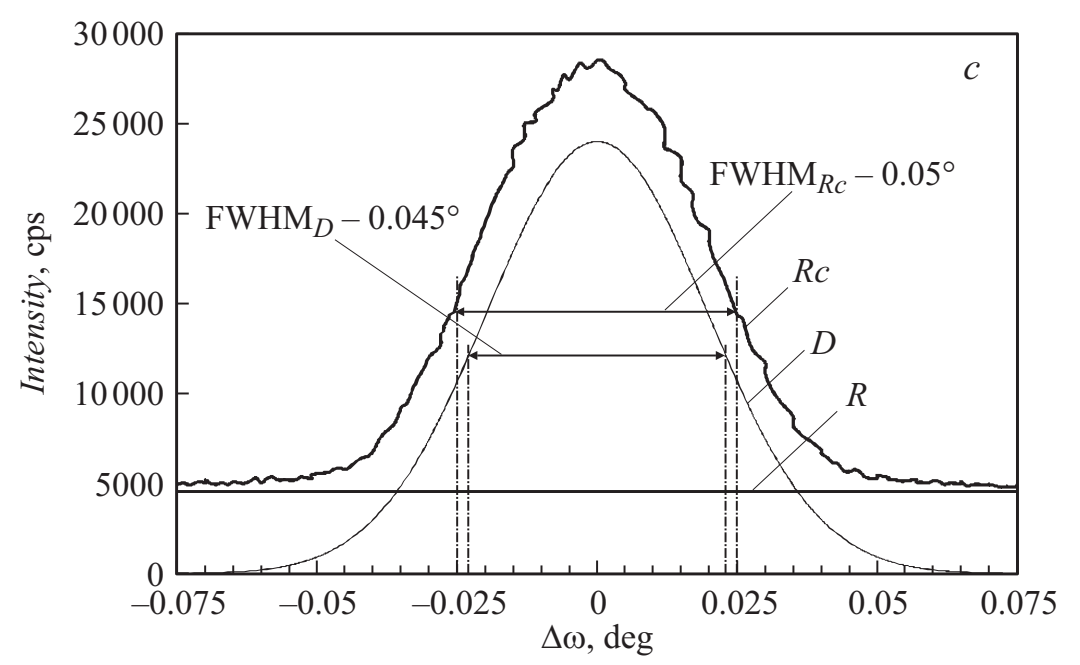

Рисунок (продолжение).

всей кривой качания. Кроме этого, наблюдалось возрастание $\mathrm{FWHM}_{R c}$ до $0.25 \pm 0.05^{\circ}$, что указывает на повышение плотности дефектов в пленках и на ухудшение их кристалличности. При снижении $\tau_{P E}$ до $6 \mathrm{~s}$ происходило повышение величины $\mathrm{FWHM}_{R}$ до $6.0^{\circ} \pm 1.5^{\circ}$. При этом из-за уменьшения $I_{D} / I_{R}$ до ноля величины $\mathrm{FWHM}_{R c}$ и $\mathrm{FWHM}_{R}$ сравнивались. Дальнейшее уменьшение длительности $\tau_{P E}$ до $3 \mathrm{~s}$ приводило к синтезу аморфных образцов, у которых на рентгенограммах отсутствовали рефлексы, связанные с AlN.

В заключение следует отметить, что наилучшим результатом проведенного исследования являлись образцы, выращенные при длительностях плазменной экспозиции $20 \mathrm{~s}$ и при температурах в диапазоне $250-280^{\circ} \mathrm{C}$. У этих пленок $I_{D} / I_{R} \approx 6$, a $\mathrm{FWHM}_{R c} \approx 0.045^{\circ} \pm 0.003^{\circ}$ $(162 \pm 11 \operatorname{arcsec})$. Для сравнения, величина $\mathrm{FWHM}_{R c}$ у синтезированных нами образцов меньше в четыре раза, чем у ориентированной пленки AlN $\left(\mathrm{FWHM}_{R c}=670 \operatorname{arcsec}\right)$, выращенной методом PEALD [16] на подложке сапфира с подслоем нитрида галлия при температуре $500^{\circ} \mathrm{C}$.

Таким образом, на основании проведенных исследований было установлено, что методом плазмоактивированного атомно-слоевого осажде-

Письма в ЖТФ, 2017, том 43, вып. 1 
ния с использованием источника емкостно-связанной плазмы можно выращивать ориентированные кристаллические пленки нитрида алюминия при температурах от $210^{\circ} \mathrm{C}$. С увеличением длительности плазменной экспозиции и при повышении температуры подложки кристалличность пленок возрастает. По нашему мнению, повышение кристалличности пленок с увеличением $\tau_{P E}$ происходит из-за увеличения временного промежутка, в течение которого хемосорбированные частицы могут участвовать в диффузионных процессах, приводящих к образованию более крупных зародышей. При этом энергию для осуществления актов диффузии эти частицы получают при взаимодействии с плазмой. Следовательно, в случае использования метода PEALD негативные эффекты, связанные с уменьшением температуры, в частности понижение кристалличности пленок, можно компенсировать путем увеличения длительности плазменной экспозиции.

\section{Список литературы}

[1] Sowers A.T. et al. // Appl. Phys. Lett. 1997. V. 71. N 16. P. 2289-2291.

[2] Sahyoun $W$. et al. // IEEE TUFFC. 2011. V. 58. N 10. P. 2162-2170.

[3] Ivaldi P. et al. // Frequency Control Symposium (FCS). 2010. P. 81-84.

[4] Tsai D.-S. et al. // Sci. Rep. 2013. N 4. P. 2628.

[5] Clement M. et al. // Ultrasonics. 2004. N 42. P. 403-407.

[6] Ратников В.В. и др. // Письма в ЖТФ. 2016. Т. 42. В. 8. С. 61-69.

[7] Bläsing J. et al. // J. Appl. Phys. 2009. V. 105. P. 033504 (1-9).

[8] Kakanakova-Georgieva A. et al. // J. Crystal Growth. 2012. V. 338. N 1. P. $52-56$.

[9] Xi Y.A. et al. // Appl. Phys. Lett. 2006. V 89. P. 103106.

[10] Matsunami N. et al. // Adv. Mater. Phys. Chem. 2013. N 3. P. 101-107.

[11] Lee Y.J. et al. // Thin Solid Films. 2004. V. 446. N 2. P. 227-231.

[12] Bosund M. et al. // Appl. Surf. Sci. 2011. N 257. P. 7827-7830.

[13] Alevli M. et al. // Phys. Status Solidi A. 2012. V. 209. N 2. P. 266-271.

[14] Motamedi P. et al. // J. Crystal Growth. 2015. N 421. P. 45-52.

[15] Alevli M. et al. // J. Vac. Sci. Technol. A. 2012. V. 30. N 2. P. 021506 (1-6).

[16] Nepal N. et al. // Appl. Phys. Lett. 2013. V. 103. P. 082110.

[17] Boulle A. et al. // J. Appl. Phys. 2005. V. 97. N 7. P. 073503. 